\title{
PODER Y TRADUCCIÓN COLONIALES: EL NOMBRE DE DIOS EN LENGUA DE INDIOS*
}

\author{
Esperanza López Parada \\ Universidad Complutense de Madrid \\ elopezpa@filol.ucm.es
}

\section{RESUMEN / ABSTRACT}

El descubrimiento de América coincide cronológicamente con el interés despertado en el humanismo renacentista hacia las lenguas vernáculas. El hallazgo de nuevos pueblos con nuevas formas de hablar que no podían enmarcarse ya dentro de la sintaxis latina redundó en una masiva producción de gramáticas, diccionarios, vocabularios, tesauros y manuales para el aprendizaje de las voces nativas, así como de sermonarios, cartillas y catecismos de la doctrina cristiana traducidos a las mismas -no solo a las principales como el quechua, náhuatl o aimara sino a rarezas como el araucano, mosca o allentiac- para la evangelización y bautismo de sus hablantes. Cualquier intento de analizar los primeros contactos en el encuentro intercultural americano tiene que habérselas con esta cuestión de la traducción y con los debates que se dirimieron acerca de su oportunidad y conveniencia. A modo de precipitado o paradigma de todos ellos, cabe citar cómo se resolvió el problema colateral de verter el nombre del dios cristiano a las lenguas indígenas, problema al que se dieron soluciones muy distintas que el presente estudio solo pretende enunciar.

PALABRAS ClAVE: traducción y poder colonial, lenguas indígenas, religión, idolatría.

The discovery of America was recorded chronologically in the European policy for vernacular languages that Renaissance humanism would subsequently generate and institute. The discovery of new peoples with new forms of speech that could not already refer to Latin grammatical

El presente trabajo se inscribe dentro del Proyecto I+D+i del Ministerio de Economía y Competencia del Gobierno de España que, con la referencia FFI2012-37235, se propone el estudio de las relaciones entre "Intertextualidad y Crónica de Indias (la variedad discursiva de la escritura virreinal)". 
rules resulted in the mass production of grammar manuals, dictionaries, vocabularies, sermonaries, catechisms and thesauruses of native languages-Quechua, Náhuatl, Aimara, etc.- that, responding to the understanding of language as the primary tool of imperialism and religion, sought the rapid evangelization and control of indigenous subjects in their own language. Every effort in order to analyze those early instances of cultural encounter has to do with the topic of translation as its main condition, the most fundamental and basic one, and with the necessity of reflection and the argument, raised in that time, about its convenience. As a paradigm of both-encounter and reflection-, this article focuses on the different ways in which it was faced the challenge of translating the name of the truly god into the selvatic indian languages.

KEY WORDS: Translation and colonial power, indian languages, religion, idolatry.

I. Si en los Comentarios Reales el Inca Garcilaso explicaba el vocablo quechua huaca y las múltiples acepciones que reúne, en sus Apostillas a López de Gómara hubo de detenerse en una matización de orden gramatical. Cuando huaca se utiliza dentro del léxico sacro está actuando en tanto nombre propio y se utiliza para invocar aquello mismo que los españoles llaman Dios. Vale por el apelativo absoluto de la divinidad. De ahí su abundancia en las plegarias indígenas, una abundancia que no puede sino erróneamente esgrimirse en síntoma de reincidente politeísmo. Los incas apelan a su dios con la veneración reiterada con que los cristianos también lo hacen.

que del nombre c[on] [que] los Indios [del] piru no[mbran] al Idolo [no] [se] puede d[edu]zir el v[erbo] idolatra[r] [por]que es nombre $\mathrm{p}$ [ropio] para tod[os] [los] dioses [...] como el [que] otros [tienen] para 11[amar] a Dios... (87).

Evidentemente, Garcilaso emplea el testimonio de la gramática con una finalidad negociadora: está interesado en la defensa de un primitivo monoteísmo incaico, por lo que prefiere sortear los peligrosos significados de ídolo o tótem de clanes. Pero lo interesante reside en que, al ser nombre propio, el Inca lo percibe sin traducción posible, sin referencialidad directa: es todo y nada, posee la ubicuidad y concreción de lo inasible. Tampoco -y eso es lo subrayable- tiene traslación correcta a la lengua de acogida. Opera precisamente con la opacidad semántica con que los españoles lo desatienden. 
II. En los albores del siglo XVI, con el hallazgo de las Indias, cristiandad y traducción entablan una relación indisoluble, sin la que no puede pensarse ninguna de las $\operatorname{dos}^{1}$. Y de hecho, durante la etapa colonial y los virreinatos, las tareas traductoras que del español se realizan a las diversas lenguas nativas constituyen una operación casi exclusivamente desenvuelta dentro del ámbito religioso, pero con una -todavía hoy- no evaluada importancia en la construcción social, política e identitaria de aquella realidad.

El aventurero recién llegado allí experimenta, como no se había dado antes ni entre los más audaces viajeros de la antigüedad, la constatación directa de la necesidad traductora, constatación de una diferencia lingüística que ya no permite ser solventada con su repudio dentro del marchamo de lo bárbaro y la adjudicación al otro de una simplista carencia de habla.

Todo lo contrario. América hierve de lenguas y de hablantes y Luis Jerónimo de Oré, en el prólogo de su manual para curas en el Perú, reconoce "la falta que hay" en sus provincias "de algunas traducciones necessarias (...) en las lenguas generales de aquella tierra, Quicchua o Aimara", las cuales, obligado "por el servicio de Dios", él complementa con "Puquina, Mochica y Guarani" (B2). Si la poliglosia descubierta en el Nuevo Mundo -recordemos la cifra total de un millar de idiomas que Américo Vespucio calcula, según lo escuchado en las Antillas² ${ }^{2}$ pone a prueba la expansión eclesiástica y la

1 "Translations matter so much in the history of early modern Catholicism that one might easily argue "no translations, no spiritual renewal, no Catholic Reformation" -at least not the kind of Reformation that historians now seem to take for granted" (Eire 83).

Para Bruce Mannheim (“Gramática colonial” 209), la constatación de ese lazo entre operación traductora y operación de conquista supone una apertura multidisciplinar en los parámetros epistémicos de su estudio, hasta el momento encerrados en focalizaciones documentales, referenciales o aisladamente historiográficas. Para evitar la reificación de las lenguas indígenas a que parecen abocar ciertos análisis microsociológicos, Mannheim viene abogando por un acercamiento integral, del que son ejemplo la mayoría de los artículos citados en esta sucinta presentación a la cuestión, para la cual se ha decidido trabajar exclusivamente con las traducciones religiosas de la lengua del imperio a las nativas halladas en las Indias (Ver Burkhart, Dedenbach-Salazar, Decoster, Durston, Harrison, Gruzinski, Itier, Jooken, Kartunnen, Klor de Alba, Lisi, Lienhard, Lockhart, MacCormack y por supuesto el propio Mannheim, entre otros).

"In fine, navigammo altre 300 leghe per la costa, trovando di continuo gente brave e infinitissime volte combattemmo con loro. E pigliammo di essi opera di venti, fra i quali avea sette lingue che non s'intendevano l'una all'altra; dicesi che nel mondo non sono più che 77 lingue e io dico che sono più di 1000, che solo quelle che io ho udite sono più di 40 " (Vespucci 81). En este caso, como en las demás citas de fuentes, he actualizado la puntuación 
fundamentación del poder de la Iglesia, la curia tiene a bien proveerse de instrumentos lingüísticos para extender la doctrina, para llevarla y traerla por extensiones impensables, desde las parroquias "sufragéneas del Cuzco, Quito, Charcas, Chuquiavo, Sancta Cruz de la Sierra, Tucumán, Río de la Plata y hasta Brasil inclusive, en distancia de mil y ochocientas leguas": una doctrina traducida a las voces nativas, estudiada en sus gramáticas, transportada a lomos de mula y luego incluso devuelta a Roma, donde será ofrecida al papa Paulo Quinto "besándole sus santissimos pies" (Oré, "A los curas de los Indios del Pirú” B2).

Con la fe peregrina, los catecismos se versionan en una amplitud y cantidad que sorprende como el reportaje de una nueva Babel indiana: los curas párrocos son capaces de traducir la doctrina al quechua, aimara, náhuatl, maya, araucano, pero también al zapoteco, michuacano, mixteco, a la lengua brasílica, cumanagota, callínago, al moxo boliviano, kariri, yunga, lule y tonocoté en las misiones del Chaco o mixe de Oaxaca, incluso tras la expulsión de los jesuitas, principales promotores de este Pentecostés de bolsillo y de su floresta de artes, lexicones y diccionarios en todas y cada una de esas formas -hasta entonces irredentas- de hablar ${ }^{3}$.

Y si primeramente la operación se vio favorecida por la conveniencia expresada en el Concilio de Trento de postergar en la iglesia el exclusivista latín a favor de las mucho más comprensibles lenguas vernáculas, lo cierto es que esta nativización idiomática de la doctrina en Indias se percibió muy rápido como un tipo de oportunidad transculturadora lo suficientemente

y la grafía, sustituyendo tipos arcaicos $\left(-\int,-c ̧\right)$ y modernizando otros. A veces, cuando resultaba imprescindible para favorecer el sentido, he acentuado.

Si es falso defender que en sus manos quedó toda la labor traductora pastoral en las Indias occidentales, es cierto en cambio que la orden, emulando a su padre fundador que alcanza la fe precisamente leyendo traducciones vernáculas de dos obras latinas, la Leyenda Áurea de Jacobo de la Vorágine y la Vita Christi de Ludolf de Sajonia, parece especialmente sensibilizada hacia la empresa. De hecho, Ignacio de Loyola es el primer santo creador de una orden que hace gala de una cultura popular, imaginera, impresionista y vernácula. Burke cuenta 250 jesuitas traductores en Europa desde la fundación de la Compañía hasta el XVII, entre los que se pueden nombrar algún fraile polaco, alemán, francés, flamenco, holandés y hasta checo. Ahora bien, si los jesuitas parecen tomados de una verdadera manía traductora que Burke se atreve a calificar incluso de conspiradora, no tanto para extender el poder de la Iglesia como de la orden misma, también la Reforma se estaba pertrechando de múltiples catecismos y textos de apoyo doctrinario en lenguas tan varias y casi exóticas como el estonio, el lituano o el ruso (Burke 15 y 16). Para el catolicismo esa prolijidad no es europea sino americana. 
arriesgada para abandonarla a la eventualidad de cada caso. Los diferentes sínodos celebrados en América, aplicando los principios del tridentino, se obstinan en fijar modelos autorizados y asentar traducciones canónicas de los textos ecuménicos: se habla claramente de evangelizar en quechua o en náhuatl pero con fórmulas de apoyo, con manuales orientativos consensuados que impidan el libre albedrío traductor o el azar idiomático, todo lo cual sirve para informarnos de la naturaleza sospechosa con que la traducción es observada en el Nuevo Mundo en cuanto actividad tan fluida y enmascarable como para estimular su vigilancia ${ }^{4}$.

El proemio o presentación de los trabajos abordados por el III Concilio Limense, por ejemplo, destina numerosas explicaciones a los contenidos de evangelización en parroquias indígenas y a su cuidada dosificación según la limitada capacidad que se les supone:

siendo como son los Indios gente nueva y tierna en la doctrina del Evangelio y lo comun de ellos no de altos y levantados entendimientos, ni enseñados en letras, es necesario lo primero: que la doctrina que se les enseña sea la esencial de nuestra fe, (...) como son las cosas que se contienen en el catecismo o cartilla, porque tratar a Indios de otras materias de la Sagrada Escritura, de puntos delicados de teología, de moralidades y figuras, como se hace con Españoles, es cosa por ahora excusada y poco útil. Pues semejante manjar sólido, y que ha de menester dientes, es para hombres crecidos en la religión cristiana.

4 Desde el II y, sobre todo, el III Concilio limeño - en el que colabora protagónicamente el padre José de Acosta- se fijan unas versiones oficiales de la doctrina para predicación de los indios, en una-también oficialmente fijada- lengua cuzqueña general. Así, contamos con el inestimable ejemplo de la Plática breve de los principios que debe conocer el cristiano para salvarse, traducida primero por Domingo de Santo Tomás y luego por los lingüistas conciliares, cuya comparativa demuestra el intento de pautar líneas con la voluntad de aplicarlos normativamente a todo el virreinato (Taylor "La Plática..."). No solo asistimos a una evolución del mensaje que la Iglesia desea transmitir a los indios, una vez que ha podido evaluar mejor sus inclinaciones y necesidades, sino en lo que al quechua se refiere, vemos también la imposición sobre el idioma nativo de gravámenes morales y jerarquizaciones idiomáticas que no encontrábamos tan claramente en aproximaciones lingüísticas previas. Y, por tanto, la sonorización de la / $\mathrm{k} /$ tras nasal, que ya detectaba Domingo de Santo Tomás, ahora se considera sin embargo la señal de un hablar corrupto, menos elegante o directamente tosco (Taylor, "La Plática..." 174). 
Pero frente a la política proteccionista y jibarizante de algunos sacerdotes, en otros casos se imaginó que el mensaje crístico, transmitido en su integridad, se abriría paso a través de los obstáculos idiomáticos para imponerse por sí mismo: la fuerza de la palabra del Mesías operaría epifánicamente sobre los oídos sensitivos del pagano, sin necesidad de su comprensión lógica. Es curioso que la traducción literal, la traducción palabra por palabra de las Sagradas Escrituras se restablezca entonces como operación consecuente con el poder casi cabalístico de éstas, cuando ya había sido puesta en cuarentena por el propio traductor de la Vulgata.

Es cierto que en ningún momento había dejado de considerarse obligatoria para el caso de la Biblia, dado que en ella el orden y elección de los verbos obedece a inspiración divina. Pero San Jerónimo, en su Carta Ad Pammachium, mantiene en torno a la cuestión una ambigüedad imprevista de la que tendrá que defenderse ${ }^{5}$. De hecho, en este texto, primer tratado de traductología que se conoce, el santo y eremita concebiría la actividad como algo que desborda el simple ejercicio de transferencia de vocablos, apoyándose para ello en autores latinos como Cicerón, Horacio, Terencio, Hilario, Plauto o Cecilio. Se trataría por tanto de verter el contenido original sin someterse a la "estructura superficial de las palabras", incluso si ese contenido viene dictado de manera directa por Dios.

Sin embargo, en el caso de la traducción pastoral en Indias, el argumento del vertido preciso de los Evangelios en las doctrinas, cartillas, en los fragmentos explicados del sermón dominical, serviría no tanto como ejercicio de fidelidad sino de perlocución: la versión literal funcionaría como un mantra o una fórmula que se realiza cuando se aplica, que llama a la conversión no racionalmente y que por tanto no precisa de adaptaciones didácticas con las que volverla asequible. Así, evitando "razones naturales", analogías, fábulas, comparaciones "para inducirlos a creer", apelando en cambio a una convicción desencadenada por la autoridad misma "del que nos las reveló",

En principio, el protocolo de la traducción en los ámbitos secular y el sagrado se percibían muy distintos en cuanto al grado de permisividad que ofrecen: máxima para la literatura profana y muy vigilada en el caso de la traducción de las Escrituras. El problema radica en que, en dicha Carta, a San Jerónimo se le ocurre ejemplificar la primera opción, la traducción aproximada, con citas de la segunda, con variantes diversas y no literales de la Biblia, sobre la base de que incluso en este caso -en el que la forma coincide con el fondo, en el que la palabra es ya el mensaje- también se puede y se debe traducir libremente, puesto que los propios Apóstoles así lo habían hecho al explicar las palabras arameas de Cristo. 
Juan Ossorio se propone traducirle al indio náhuatl las palabras exactas de la fe católica. Su confianza en la emoción persuasiva que reside en el ejercicio traductor, lo más fiel posible, de la misma le alcanza hasta para adiestrar al nativo en sus puntos oscuros.

Pero no soy de parecer que a los indios se les prediquen las cosas de la Fe trayéndoles razones o comparaciones para dárselas a entender; porque la gente de bajo entendimiento se le debe persuadir a creer las cosas de la Fe Catholica por la Authoridad del que nos las reveló que es Dios, diziéndoles desta manera: Esto sabemos ser Verdad, muy firme y cierta, porq[ue] Dios la dixo (segun està escripto en la sagrada Escriptura); el qual nunca mintió ni puede mentir. Y esto se les debe repetir muchas vezes y sobre cada articulo de la Fe. Pero traer comparaciones o razones naturales para persuadirlos a creer tampoco es mi parecer (...) (Ossorio I).

Como única concesión pedagógica, Ossorio se permite la proposición doctrinaria de los misterios más densos a través de la virtualidad comunicativa del diálogo renacentista que él utiliza sobre todo en la explicación del dogma de las tres personas divinas, de acuerdo con el símbolo Quicumque vult que formulara San Atanasio. Siguiéndolo aplicadamente, Ossorio alcanza incluso a traducir las complicadas etiquetas con que Dios, el Hijo y el Espíritu desenvuelven sus relaciones en el triángulo teológico que dibujara el santo alejandrino (Fig. 1). En él se nos expone plásticamente que cada uno no es ninguno de los otros -el Padre no es el Hijo que no es el Espíritu Santo- pero que todos confluyen en su tripartita naturaleza divina. Además, en el cuerpo del texto, esta compleja estructura se explica bajo la forma bicápite de una conversación distendida entre maestro y discípulo, un diálogo que se desenvuelve al paso de la paulatina conversión del alumno. Pero, por tanto, lo que se traduce o traslada de una cultura a otra no es tanto la doctrina-imposible de verter en su abusiva oscuridad-como el recurso persuasivo con que se busca imponerla: recurso elocutivo y género por antonomasia del humanismo vigente. 


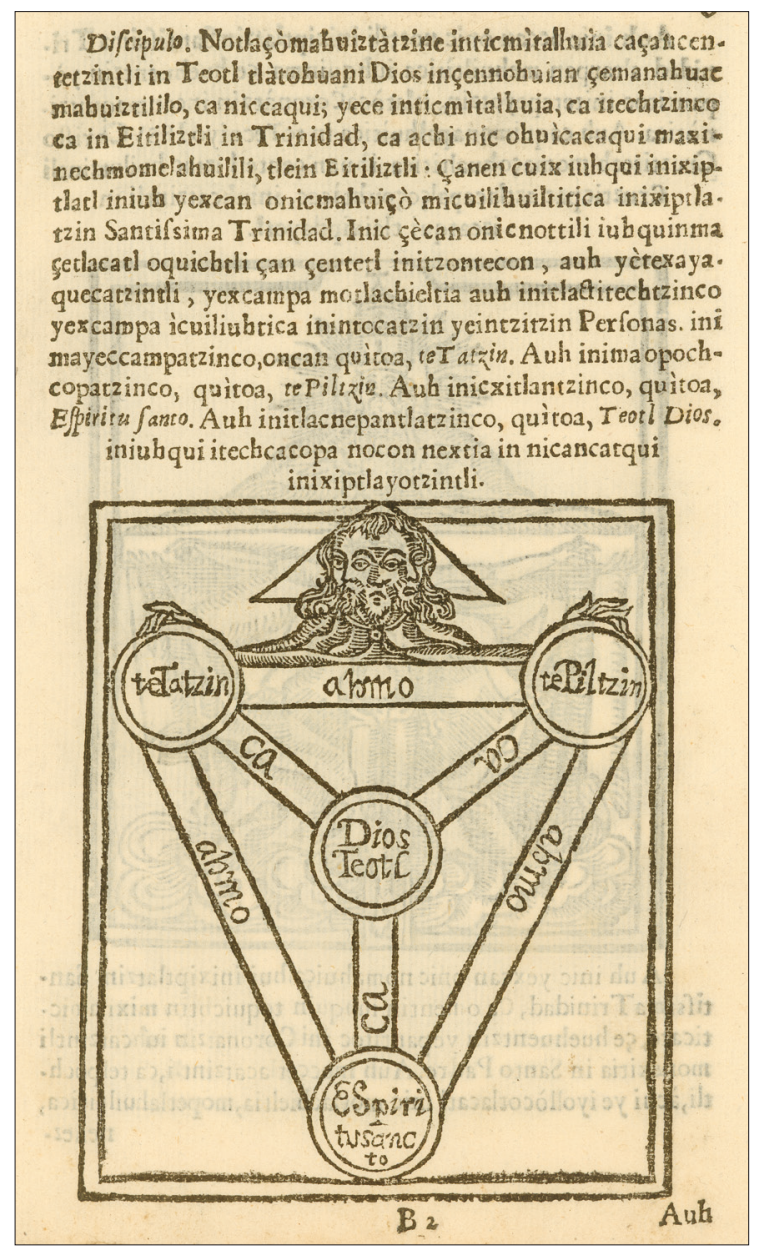

Fig. 1: "Santísima Trinidad". Ossorio, Juan. Apologia, y declaracion en dialogos en la lengua mexicana, del symbolo de San Athanasio, y confessionario breve, 1653. Cortesía de la John Carter Brown Library.

Aun así, todo el pasaje reside en esa fórmula quicumque que encabeza la oración de San Atanasio y cuyo lema viene a afirmar que "quien quiera puede"; es decir, el que desee salvarse en el seno de la Iglesia está ya salvado gracias a su inclinación en ese sentido y mediante la aserción emocionada de su doctrina, aserción por otra parte implícita en dicho deseo. 
A partir de ahí, el conversatorio entre un sacerdote y un indio sobre el poder de la voluntad en la salvación de cada quien y la importancia, sin más, de la aceptación creyente en el espíritu, al provocar dicha aceptación durante el ejercicio de la charla y al suponer que la doctrina se abriría paso en la conciencia del lego por su propio poder apelativo, ¿estaría realizando la salvación misma en el proceso escrito de su predicación dialogada?

Desear y afirmar lo que se desea es, en principio, un acto contenido en el discurso que trata de la vinculación entre ambos. La mayor parte de estos textos pastorales bilingües y muchos de los escritos y trabajos traductores -incluidos los diccionarios, tesauros, guías y mecanismos para favorecerlos- incorporarán, de igual modo, una alta y fascinante dimensión performativa, ya que intentan llevar a los otros a la conversión, mediante el efecto discursivamente expuesto de la inteligibilidad sin trabas, dada per se, emanada naturalmente del poder del mensaje mismo e inspirada probablemente en el modelo espectacular de Pentecostés. Recordemos que para Gerónimo de Mendieta la predicación en lengua nativa, al pretender la comprensión total y casi milagrosa con el indígena, debía colocarse bajo la protección de aquel episodio. Entonces la performance a la que aquellos textos traducen la fe, y se traducen ellos mismos, hace de su escritura una compleja mecánica de causas y resultados, un juego redondo por el que la traducción deja de ser un medio y se convierte en un fin con el que persuadir, convencer y testimoniar el asombroso y deseable don de lenguas que los hace posibles.

III. Pero la abundancia y diversidad de las lenguas nativas no siempre se percibió de un modo tan comprensivo: muy al contrario, evidenciaba una inmadurez religiosa con su dispersión en deidades aberrantes y acabó por generar escrúpulos sobre el empleo de nomenclatura pagana para rezar las nuevas oraciones o, por lo menos, un amplio y ambicioso debate de dimensiones tan ideológicas como semánticas.

Pronto los teólogos de las Indias aplicarían el corte tajante de una cirugía preventiva: dios es dios y no puede ser nombrado de otro modo ni menos aún traducido a las irregulares y selváticas vocalizaciones de los indios de América. Dentro de un proceso que concernía menos a la justeza de la expresión que a las exigencias jerarquizadoras de la imposición imperial, los nombres del Padre, de la Virgen, de Cristo, los sacramentos o los dogmas acabaron por incorporarse tal cual, en un castellano en bruto dentro de los sermones pronunciados desde los púlpitos de las cristianísimas Indias 
conquistadas, "para que quedara bien precisa la diferencia entre las divinidades del paganismo y el Dios único de los cristianos" (Ricard 131-132). Incluso, en este particular, José de Acosta no parece preocupado si expresiones como cruz, ángel o matrimonio se mantenían sin traducir en medio del catecismo: el uso conseguirá suministrar su sentido a los nuevos buenos cristianos ${ }^{6}$.

La cuestión no era inocua, en tanto comprometía la integridad de la "traditio" de la revelación. Y probablemente algo chirriaba disarmónico en los oídos eclesiásticos si se la pretendía traducir a la terminología religiosa autóctona. Por un lado podía generar peligrosas concomitancias, por el otro desvanecía en una galaxia de sentidos segundos la prístina y unívoca advocación del misterio católico. Taylor se pregunta en efecto cómo sonaría esa abundancia repentina de un dios múltiplemente citado bajo aspectos diversos y cómo es que podrían seguir el laberinto oral de sus múltiples invocaciones en español aquellos nativos malamente adoctrinados y forzados a un bautismo de urgencia ${ }^{7}$.

La solución no resultó, desde luego, enteramente satisfactoria, pero en general el cura traductor temía mucho más la peligrosa caída en la insinuación politeísta que podía darse mediante el empleo de una voz indígena. Ocurría entonces como vimos con la expresión huaca entre los incas. También Bernardino de Sahagún había observado los valores múltiples aglutinados en el sustantivo teutl, que significa "dios en náhuatl" y además "plantas, animales, astros, montes, ríos", cualquier criatura que sea eminente y subrayable, las formas bellas de la naturaleza, lo grande y feroz, lo malo o lo bueno en grado de excelencia y en una proliferación inabarcable ${ }^{8}$.

6 "... no hay que preocuparse demasiado si los vocablos fe, cruz, ángel, virginidad, matrimonio y otros muchos no se pueden traducir bien y con propiedad al idioma de los indios" (Acosta 75).

$7 \quad$ "L'ambiguité de l'emploi de Dios, écrit constamment avec une majuscule dans le sens de l'être unique désigné par se nom mais aussi dans celui d'une catégorie de puissances surnaturelles que l'on aurait pu appeler huacas si ce terme n'avait pas été retenu pour définir les idoles, les faux dieux par excellence, crée un problème de traduction. (...) Cependant, les chrétiens indigènes, de conversion récente, en écoutant un message purement oral, devaient se perdre dans ce jeu de distinctions pas très évident et compliqué de surcroît par le fait que Dieu le Père, Dieu le Fils et Dieu le Saint-Esprit, tout en étant trois, n' [était] qu'un seul être, un seul dieu" (Taylor, "La Plática" 178).

"A cualquier criatura que vían ser iminente en bien o en mal, la llamaban teutl; quiere decir dios. De manera que al Sol le llamaban teutl por su lindeza; al mar también, por su grandeza y ferocidad. Y también a muchos de los animales los llamaban por este nombre 
Tanta era la capacidad denotativa de las lenguas nativas que el extirpador en Huarochirí, Francisco de Ávila, califica sus vocablos de difíciles por preñados, como una madre gramatical y fecunda: embarazados morfemáticamente de una significación escasamente reductible, de modo unidireccional, a su primer sentido castellano. Ávila utiliza esta metáfora en el entorno del misterio de la Encarnación para su "Sermón de la Natividad", al percibir la capacidad generativa de los diversos lenguajes cuyo léxico, grávido semánticamente, debe desentrañarse poco a poco, confiando siempre en la capacidad ecuménica de la fe. De nuevo, Ávila parece alinearse con el postulado de un mensaje crístico capaz de dotarse de los mecanismos necesarios para su propia difusión. Para él, por ejemplo, los Apóstoles inspirados por el Espíritu Santo se habrían expresado en todas las lenguas, incluidas aquellas todavía no descubiertas. Esta especie de panglosia futurista le sirve para incluir por adelantado el Perú en el diseño universal de la Iglesia primitiva:

Y para que en toda la redondez de la tierra y en quales quiera pudiessen hablar les enseñó también las lenguas; y assí supieron hasta las lenguas desta tierra, la Quecchua, la Aimara, la Ccolla, la Puquina, la de los andes y las de los Negros (Ávila, "Sermón de Pentecostés", I, 315).

Pero insistamos que no siempre todo fue tan provisorio y la traducción de textos evangélicos -ya mirada con máxima alerta en la Península- tampoco fue bienvenida en las Indias, generando suspicacias y comportamientos cautelares hasta la paralización de la misma. Frente al pasaje de arranque del Evangelio de San Juan, el predicador bilingüe y nacido en el Cuzco, Ivan Roxo Mexía, que podría estar programando una versión quechua del mismo", desestima la idea al tropezarse con esa frase "Y en el principio era

por razón de su espantable disposición y braveza. Donde se infiere que este nombre se toma en buena y en mala parte. Y muchos más se conoce esto cuando está en composición como en este nombre teupilzintli, "niño muy lindo, teupiltontli, "muchacho muy travieso o malo". Otros muchos vocablos se componen desta misma manera, de la significación de los cuales se puede conjecturar que este vocablo teutl quiere decir "cosa extremada en bien o en mal" (Sahagún 983). Para el estudio de esta cuestión entre los franciscanos de Nueva España, ver Murillo "El dios cristiano..." y para el debate teológico desencadenado a partir de esto, Gil $29-40$.

Al menos, nos declara su intención de traducir literalmente el Nuevo Testamento: "Quedándome Dios vida, como este primer año he dado en este Arte los Preceptos que faltaban a los Primeros, saldrá despues a luz la Traduccion literal de los Evangelios que he empezado a dictar en la Catedra. Para Gloria, y honra de Dios, de su Santissima Madre MARIA, Concebida 
el Verbo", inaplicable en el léxico indígena donde principio es el alba de los tiempos y no el inicio de la eternidad y donde Verbum nunca equivaldría a la voz quechua correspondiente simi. Esta señala la palabra cotidiana, la lengua participada colectivamente ${ }^{10}$, inapropiada también para Francisco de Ávila por similares razones. Nombraría el lenguaje de todos los días y todos los indios, la enunciación sucia en la boca conjunta de la tribu en pecado. Es más, simi es el orificio de la cara por donde salen las emisiones de la voz, algo completamente vulgar y común, un órgano de la fisiología inconveniente por tanto a las cuestiones del cielo:

En la lengua de Indio dezimos simi a esta ventana o agujero que está en el rostro, donde está la lengua y dientes. Y también a las palabras que hablamos dezimos simi, porque salen por allí (Ávila, "Sermón de Natividad" I, 59).

IV. Podríamos pensar entonces que el reconocimiento de la poliglosia imparable del Nuevo Mundo se viviría de un modo tan desestabilizador como esta constatación de la no igualdad entre las variantes dialectales que la provocaban: esa experiencia radical de la no traducibilidad completa de vocablos que insinúa una distancia entre los modos de decir no siempre restañable. La búsqueda de significados aproximativos, la elocución de contenidos o la introducción directa de los conceptos más rebeldes suministra una experiencia del fracaso traductor que, si para Walter Benjamin parece inherente a la diversificación de las lenguas, también abre huecos de malentendido, frías parcelas de desconocimiento mutuo. Lógicamente, fueron las voces culturales y religiosas las más reticentes a una traslación directa,

sin pecado Original, y del Santo Angel de mi Guarda. Y para bien y aprovechamiento espiritual de las Almas de los pobres Indios deste Reyno" (87v).

10 "Todas las vezes que el vocablo (según la propriedad de la Lengua) inmuta la propriedad del sentido Literal y Catolico del Euangelio se ha de excusar el correspondiente, perifraseandolo con Frasse que ajuste al sentido del Euangelio. V.g. Ioan. I. In principio erat Verbum, Deus erat Verbum, Verbum erat apud Deum. Donde el In principio no se ha de dezir por el vocablo que al Principio le corresponde en la Lengua, que es Ccallarij; porque este significa en su propriedad, Principio de Tiempo, y el Euangelista habla del Principio sin principio dela Eternidad. $\uparrow$ Ni la palabra Verbum se ha de dezir por Simi que le corresponde. Porq esta significa en su propiedad el Verbum oris y el Euangelista habla del Verbo Eterno del Padre que es su Vnigenito Hijo" (85v). 
generando soluciones más o menos artificiales junto a polémicas alteraciones de su semantismo. Términos inasibles -supay, por ejemplo, entre los incas, no equiparable al demonio católico que Pierre Duviols o Gerald Taylor estudian en la volubilidad de sus connotaciones; así como el equivalente mexica tlacatecolotl, aceptado al final impropiamente con ese valor, que en realidad significa brujo o nigromante (Burkhart 41)- constituyeron verdaderos desafíos traductológicos. Detrás de las soluciones adoptadas es posible percibir toda una casuística variadísima y a veces de direccionalidad contraria a la presupuesta. Sin duda, operan en ella prejuicios ideológicos, algunos de los cuales actúan de modo menos obvio a lo que esperaríamos. Y, por supuesto, se dieron situaciones de incomprensión absoluta y otras no mayoritarias y excepcionales de apertura y dinamismo, cuya misma rareza implica, sin embargo, su consideración y cómputo dentro de una observación más amplia y menos prejuiciada del fenómeno.

El propio Roxo Mexía, que rechazaba el empleo desacertado de simi por verbum, dibujando un giro inesperado al final de su Arte de la lengua general del Perú (1648), propondrá la sustitución de las expresiones no versionables por trucos más o menos convincentes. Llega a hablarnos de la posibilidad de ayndiar verbos, de parafrasear sintagmas y hasta de provocar ex profeso una sensación de familiaridad entre los misterios cristianos y la expresividad autóctona, adaptando aquéllos a la enunciación del otro hasta hacer de la traducción el ejercicio de invisibilidad en que ya empezaba a conceptuarse. Lejos de ser una pretensión exclusivamente moderna, la ilusión de transparencia buscada al desvanecer las huellas traductoras en el resultado traducido, deja ya sus marcas, según Venuti, en las domesticaciones con que se gestionan versiones literarias para la Inglaterra isabelina. John Dryden exige en ese momento una cualificación plena en el conocimiento de las dos realidades que se contactan hasta la modificación de la propia en el servicio de captación de la ajena. Pero ¿cómo aceptar en el entorno religioso la alteración del mensaje, si ello permite limar la extrañeza de su implantación en la cultura receptora? ${ }^{11}$.

En ese sentido, para conseguir un grado tal de invisibilidad traductora, en una nueva vuelta de tuerca imprevista, Roxo Mexía aconseja al cura mimetizarse y sumergirse en el mundo de la lengua a la que traduce, dentro

11 Schulte 1-10. Para el concepto de invisibilidad traductora en la Inglaterra del XVII, vid. Venuti, The Translator's Invisibility 35. 
de un comportamiento integral lingüístico para el que halla modelo y guía en el singular comportamiento de San Pablo. Empeñado en la conversión de los judíos, el Apóstol vivirá entre ellos, se vestirá, comerá, se portará como ellos y hablará su lengua como el primero de los hebreos.

Qvanto importe para la Predicación del santo Evangelio (medio único para la salvacion de las Almas) el saber la propriedad de la Lengua en que se predica, lo entendió bien el Predicador de las Gentes, San Pablo. Pues para predicar a los judios - escribe a los de Corinto- vivia como judio, hablaba como judio y se transformaba en judio: Ex factus sum Iudceis, tanquam Iudceus, vt Iudcos lucrarer ${ }^{12}$.

Se trataría entonces de alentar una conducta de total inmersión en la vida pagana que halla en predicarle al nativo en su vocabulario habitual la vía más eficaz para moldear su alma. La táctica, plenamente justificada por la importancia trascendental del bien a conseguir, postula en última instancia un cierto pragmatismo mesiánico en esta especie de flexibilidad teológica, para la cual no hay artimaña indebida ni medio transmisor proscrito en la propaganda sin fronteras de la fe. Hay que subrayar que, convertido en el predecesor del antropólogo de campo, el sacerdote pretendería una mezcla y confusión igualitaria con el pueblo que bautiza. Dicha dinámica exige de sus promotores la labilidad presupuesta a la tarea y una capacidad de adaptación y convivencia tras la cual no es difícil intuir otras intenciones escondidas bajo esa trampa ilusoria de la traducción en tanto operación neutra y multicultural.

Es evidente que una cotidianeidad de tal calibre con la lengua dominada -hasta ser un nativo más entre los nativos-obedeció a una finalidad redentora e integradora por parte del poder imperial, que era el que podía permitirse esas "familiaridades exóticas" en cuanto ocupaba el extremo vencedor de tales contactos. Y desde luego puede que este consejo de una identificación casi total con el ámbito al que se traduce, a fin de estimular en él el deseo de bautismo por contagio, obedeciera a un último resorte de conquista espiritual tan avasalladora como la física y territorial, pero la confusión propiciada

12 Y el razonamiento de Roxo Mexía continúa apoyando esta simbiosis con la cultura meta: "Diligencia tan necessaria, que sin ella no se pudiera conseguir el fin glorioso de la conuersion de los infieles, porque: Quomodo audient? ¿Cómo entenderàn si el que predica no se proporciona el estylo y lenguaje del que le oye? ¿Cámo abraçaràn la ley Euangelica que se les propone sino la sabe explicar el que la enseña? ¿Ni cómo dexaràn sus Idolatrias si las palabras no ajustan al intento?". 
en virtud de ésta también deja sus réditos en la conducta del dominante. Probablemente en el proceso se comprometerían ciertas transculturaciones, ciertos trasvases en los que interpretar más consecuencias que la mera motivación imperialista.

Por lo menos, la paradoja de convertir al otro en función de convertirme yo en él diseña un bucle difícilmente reductible y un cierto escándalo identitario que, para Venuti, se encuentra en la base de todo proceso traductor que se precie ${ }^{13}$. De ahí se deriva el interrogante sustancial que invierte los polos del ejercicio y se pregunta en última instancia hacia y desde dónde se traduce, en realidad. Ya que, al fin y al cabo, lo que se propicia ahora no es el sometimiento del idiolecto bárbaro a las normas del conquistador sino lo contrario, la transformación del mensaje evangélico según usos y hábitos de esa autoctonía subordinada a la que se predica, con la voluntad subyacente de volverlo maleable y aceptable a la misma.

V. Por tanto, la impresionante producción y trabajo con las lenguas nativas durante la Colonia no deja de resultar ambivalente y suscita dudas sobre la intencionalidad de la misma. Para Walter Mignolo, estos esfuerzos de normativizarlas a través de la conceptualización y redacción de sus gramáticas operó de modo contraproducente, recortando la riqueza oral de los pueblos hallados para que entraran en los moldes de la sintaxis occidental y de las leyes morfemáticas del latín como unidad de medida o lecho de Procusto sobre el que se ajustaron las hirvientes y variadísimas expresividades del Nuevo Mundo.

Si bien Mignolo precisa las buenas intenciones y la sobresaliente contribución de aquellos religiosos gramáticos por "preservar y entender lo que habían ayudado a suprimir"14, la violencia epistémica que duerme en esa paradoja entraña la desatención y pérdida de la diversidad, junto a

13 "In practice the fact of translation is erased by supressing the linguistic and cultural differences of the foreign text, assimilating it to dominant values in the target-language culture, making it recognizable and therefore seemingly untranslated. With this domestication the translated text passes for the original, an expression of the foreign author's intention" (Venuti, The Scandal of Translation 31).

$14 \quad$ "Such an observation does not deny the good intentions and the outstanding contribution of the grammarians (...) to preserve and understand that which they also helped to suppress. It merely points toward the philosophy of language and the civilizing ideology founded in their 
la postulación del modelo propio en tanto superior. Detrás de esa panoplia de gramáticas, perpetradas contra la comunicación autóctona, se ocultaría la preeminencia arrogante de esta cultura letrada que las sistematiza. Así, cuando en México Horacio Carochi constata que al náhuatl le faltan siete letras presentes en cambio en el latín, el comparatismo del hallazgo, lejos de operar como un instrumento descriptivo, actúa justificando la superioridad occidental y, por tanto, su legitimidad probada en el dominio de aquellos espacios fonológicamente tan faltos. Del otro lado de la cuestión, según Bruce Mannheim, las deficiencias de estos trabajos se explicarían por lo hercúleo de su propósito: es casi imposible hacerse cargo con el patrón latino de las variantes de inflexión quechua, por ejemplo; de sus mecanismos de derivación verbal y nominal o de las soluciones particularmente divergentes de su morfología, de sus sufijos discursivos para marcar semánticamente la afirmación, el rumor, el énfasis. Al fin y al cabo, la estructura profunda del idioma general del Perú difiere completamente no solo del español, sino del francés, el inglés o el alemán (Gramática colonial 213).

Sin embargo, se diría que este forcejeo de los gramáticos hispanos por reconocer y enunciar lo desconocido sirvió para relativizar el poder del instrumento empleado hasta el olvido, aunque a título individual, de dicho patrón. O por lo menos sirvió para volverlos conscientes de la lengua del otro, conscientes de su igual capacidad comunicativa, del rango de aquellos lenguajes en cuanto tales, de las posibilidades de su conceptualización y empleo en la transmisión del evangelio. Una conciencia despertada por la diferencia, que no puede sino subyacer lógicamente a sus esfuerzos - de otro modo ¿por qué traducir a la cháchara pueril del bárbaro?- y cuya gestión se encuentra a años luz de otros comportamientos misioneros en códigos coetáneos que han generado opuestos testimonios.

VI. El misionero Breton, por ejemplo, creador de un catecismo francés-caribe, encuentra muy deficiente la capacidad expresiva en las Antillas. Tanto que sus pobres indios a convertir carecen de la terminología básica de la ética: no tienen sustantivos para nada de lo que concierne al alma y en principio desconocen el fundamental nombre de dios.

own construction of the classical legacy to justify the colonization of Amerindian languages and memories" (305). 
La langue des Caraibes estant fort sterile pour le commerce, l'est encore plus eu égard à nostre Foy, comme ils n'ont ny Religio, pour le vray Dieu, ny croyance pour nostre Christianisme, ny moralle pour leur conduite, ny vertu, ny vice, ny peché, ny grace, ny saincteté, ny sacramens; aussi n'ont ils pas de termes pour les exprimer (5).

El problema parece muy grave y reside en una ausencia de las categorías que el nombre cubre, una falta de contenidos en la autoctonía antillana de la que deriva lógicamente la inexistencia inmediata de nomenclatura. Breton construye este argumento desde una visión simplificada y unidireccional de la composición lingüística o, probablemente, haciendo gala de un sentido común aplastante: de ese tipo sin embargo de sentido que, cuanto más común y razonable es, tanto más imposible y más errado resulta y del que sin solución de continuidad se convierte - también él-en víctima. Los caribes no han previsto un sustantivo para el pecado: de ahí que el razonamiento subsecuente implique que no tengan en el fondo ningún pecado notable por confesar, causa en cambio de la prodigalidad de vocablos de este tipo, propia de culturas que sí pecan.

Los caribes no poseen vocablos para explicar sus vicios porque no caerían en ellos y en ultima instancia no caerían en ellos porque tampoco tienen un nombre para dios, garante absoluto de toda moralidad. Y si no tienen nombre para dios, no tienen vocabulario alguno puesto que él sustenta la posible formulación de cualquier sustantivo. Lo cual ha hecho que Breton -nos revela, pesaroso ${ }^{15}$ - no haya podido escribir apenas sino la cuarta parte de un catecismo normal, ocupando el suyo la exigua cifra de 70 benditas páginas destinadas a la alegre doctrina de un pueblo beatífico pero mudo, un pueblo inocente y descreído, sin ninguna falta y aun con menos léxico.

VII. La paupérrima opinión sobre la torpeza expositiva del indio caribe contrasta con el barroco ejercicio lexicográfico de Juan de Córdoba, cuyo diccionario zapoteca, con casi 24.000 términos, se enfrenta al problema mayor de traducir el nombre de Dios. Punta de lanza de la traducción, lugar donde esta se prueba y se confirma, Juan de Córdoba descubre que sus indígenas

15 "Cette disetre à fait que ie náy pa acheué la quatriéme partie de ce catechisme qui traitte des sacraments, des vices \& des versus, que ie me suis serui (quoy que raremêt) de mots équiuallêts dans cestrois premieres que ie vous donne" (7). 
no tienen un vocablo solo, sino una diversidad morfológica sin parangón en ninguna lengua del mundo.

En principio el zapoteca cree en un dios "biuo verdadero", según Córdoba, que se corresponde con el dios cristiano y al que llama Pitàonalij, nombre compuesto del apelativo de otra divinidad -Pitào que significa "cualquier dios"-y el adjetivo "único" o nalij. Por lo tanto, un dios corriente, cualquiera de esos dioses que los indios multiplican, entra dentro de la composición morfológica del dios verdadero, del dios absoluto que se formaría en efecto añadiendo a Pitào el adjetivo con que marca su propia condición en solitario -nalij-. Como es lógico en cosas del cielo, su advocación ha de construirse mediante este oxímoron de ser uno solo y a la vez todos los posibles entre la ristra de dioses que comparten con él prefijo, como en Pitàopezélao, Pitàopèeze, Pitàozij, Pitàocoçobi, Pitàoxicala. Voces éstas que invocan respectivamente, según el diccionario, al "Dios del infierno", "el de las riquezas y mercaderes", "el Dios de las miserias y perdidas y desdichas", el "Dios de las miesses" o el "Dios de los sueños". Pero además, los zapotecos creen en el "Dios de los agüeros", el "Dios de las lluvias", el "Dios de la caça", el "Dios o Diosa de los niños, o de la generación a quien las paridas sacrificauan", el "Dios de los temblores de tierra", el "Dios de las gallinas" -que se dice Coquilào- o el sorprendente "Dios del amor" que Córdoba se apresura en identificar con el pecado de Luxuria (140-141).

Así pues, la presencia nominativa del dios verdadero del "que dezian era criador de todo y el increado" aparece listado entre las aberrantes deidades idolatradas, entre los "dioses de los indios de piedra y palo", interpuesto sin diferencia en medio de ellos. El diccionario no provee lemas separados para el uno y los otros; parece por el contrario interesado en alternarlos. Es más, multiplica las entradas del primero en una proliferación polisígnica y escandalosamente variada: después del dios cristiano e intraducible, están sin embargo todas sus cualidades y atribuciones, aquellos adjetivos que en la escolástica le corresponden sin llenar del todo su incalificable sustancia. El "Dios padre de todos y que sustenta a todas las criaturas y las rige", el "Dios principio de las cosas y criador de ellas", el que es "infinito y sin principio" o el "regidor gouernador con todos los atributos que a esto se ayuntan", todas estas apelaciones que el Pseudo-Dionisio convierte en nombres complementarios del que, sin embargo, no tiene nombre, merecen entradas independientes y sucesivas, como si en efecto se tratara de divinidades distintas, en un listado tan barroco como inexplicable y que finaliza de un 
modo borgiano y autoinclusivo con el "Dios [que es] ser todo lo dicho y deshacerlo, disponerlo y obrarlo" (141).

Igual que un humilde animalito de cierto emperador chino componía, según la clasificación de algún sinólogo confuso, toda la zoología asiática, esta última entrada apelaría, integrándolas, a todas las anteriores para -en esa dinámica- deshacerlas al cumplirlas, para agotarlas "obrándolas"; para incorporarse ella, entera y devoradoramente, toda la clasificación, todo el inventario que abismalmente, a su vez, la soporta y la incluye.

VIII. Si el dios verdadero era un atributo más en el panteón de los zapotecas, la incoherencia de ahí derivada - que el dios absoluto que lo engloba todo constituya una porción entre otras dentro del conjunto politeísta- adquiere una solución completamente distinta en manos de otros traductores como el dominico Martín de León, para quien era perfectamente factible obtener la salvación del alma en zapoteco, guaraní o aimara, como testimonia su trabajo evangelizador en tierra de Nueva España. El catecismo que publica en 1611 se llama precisamente Camino del cielo en lengva mexicana, con todos los requisitos necessarios para conseguir este fin.

León, que escribe asimismo un Manual para administrar los Sacramentos y un Sermonario, justifica la aplicación del náhuatl a cuestiones católicas con argumentos gramaticales. Desarrollado en uno de los parerga de prólogo de su libro, el primero de ellos se basa en la presencia de nombres comunes y abstractos. El náhuatl parece distinguir de manera muy precisa entre unos y otros. Si, por ejemplo, existe el término que abstrae el concepto de "superioridad" e "inteligencia excelsa", a la vez existe la variante concreta para designar lo que es inteligente y superior, aquello "principal y señalado en las naturalezas que entiende[n] y alcanza[n]"16. Dicha variante, Tlacatl,

16 "Mas se advierte, que en qualquiera lengua y ydioma, el nombre que ha de corresponder a la persona se ha de significar en concreto como supuesto y no en abstracto como forma, porque como tambien notan los Theologos los nombres concretos significan suppuestos en las naturalezas individuas, singulares y incomunicables últimamente; lo qual no tienen los nombres abstractos que se significan como comunicables a los supuestos y sujetos en quien se hallan, o pueden hallar. Y esta distinction no le falta a la lengua Mexicana, pues los que la saben bien a cada paso la encuentran y es muy facil proballo con exemplos, como Teuctli el hidalgo, Teucyotl la hidalguía, Pilli el Caballero, Pillotl la Caualleria y otros muchos que pudiera poner". “... tiene la lengua su proprio nombre abstracto, que es tlacayotl 
no puede emplearse en México con lo que está falto de lógica o de cerebro, ni con lo que tenga algún defecto o imperfección, como "partes del cuerpo" o "de otra cosa", ni menos con lo que carezca de posición y de estatus. Por esa razón, los hombres se nombran con él, pero también los ángeles y el demonio, añadiéndole para ello más y más partículas distintas que completen y separen los significados. Así, el nombre de "Dios" nace igualmente de combinar el prefijo teo con esa misma y multifuncional raíz tlacatl, a la que se puede continuar adjuntando elementos hasta formar todo un cielo creyente de sufijos o una especie de paraíso de jerarquías morfológicas:

... significando este nombre en su uso cosa racional o intellectual y no hallándose aplicado a otra cosa, bien se sigue que con gran propriedad se usara en Dios, pues es intellectual y esto puede significar el nombre añadido algun addito con que se entienda quedar determinado a significar a solo Dios. Y este nombre es Teotlacatl que suena y corresponde a persona Divina, como Tlalticpactlacatl corresponde a persona de la tierra o humana, Yluicactlacatl corresponde a persona del Cielo o Angelica y Teocatlatl tiene el adiunto Teo que es nombre proprio de Dios. Y assi, por solo él, se puede poner y significar muy propriamente persona Divina y de Dios.

El problema es que esta derivación teológico-morfemática tiene oscuras resonancias que alarman la capacidad dialéctica de Martín de León, ya que entonces podríamos considerar el nombre de dios un compuesto o un derivado, una expresión imperfecta que proviene y se construye mediante adiciones de otro étimo, en lugar de ser una voz "radical simpliciter \& absolute". Preocupadísimo por el peligro de la monstruosidad lingüística y herética que acaba de crear, León insiste en deshacer el entuerto con nuevas precisiones nominales:

Es tambien muy cierto (segun lo dicho) que este nombre (...) no se deriva de otro alguno que significa imperfeccion o partes de cuerpo; lo

que significa propriamente la superioridad entender en abstracto; como Tlacatl en concreto significa la persona o la cosa superior en entender. Y assi el nombre de suyo no significa cosa de imperfeccion, ni de otra cosa o partes de cuerpo; porque si esas significara, no se pudiera atribuyr a los Angeles ni al Demonio a quien no pertenece por no tener cuerpo" (Leon, "Razones para satisfacer la duda de que en razon deste vocablo Persona diuina a auido y su declaracion, en la lengua Mexicana, con este vocablo y término (Teotlacatl) con q[ue] queda prouado y aueriguado ser el potissimo y no auer otro que tambien lo signifique"). 
que alguno podía dezir que sale o se deriva de Tlactli, que significa un medio cuerpo de la cintura arriba, no tiene eso apariencia de verdad, porque si eso fuera, no se atribuyera a los Angeles y a los Demonios a quien no conviene razón de cuerpo.

La lógica demostrativa aun continúa por más tiempo, implicando a animales que también se designan con el pluriempleado Tlacati o a diablos que componen su condenada nomenclatura con é $1^{17}$. Y, de esta manera, la sofística en torno al nombre de Dios va adhiriendo carne léxicográfica al asador de la discusión, construyendo en efecto una corporeidad discursiva cada vez más membruda, como un órgano pleonástico que defienda a duras penas la racionalidad idiomática de su irregular crecimiento. Pero frente a los escrúpulos que -como hemos visto- otros religiosos interpusieron para el empleo de las voces paganas, el proliferante esfuerzo de Martín de León se encamina a probar la inequívoca exactitud de esa expresión, la mejor que hablante alguno pudiera emplear para la divinidad por su justicia y perfección.

El sacerdote acepta los sufijos aztecas, con todo su acumulación adiposofonológica y su inflación aglutinante por el rendimiento que arrojan en este caso específico, generando ese vocablo, teocatatl, que traduce el nombre del Dios católico y lo hace "con tanta y más propiedad que el que comúnmente usamos en romance", lo cual para mayor impacto de esta gigantoloquia firman junto con él, en el documento sorprendente que encabeza su libro, otros colegas dentro de estas lides evangelizadoras de la talla de Alonso y Francisco de Solís, Jerónimo de Zárate o Juan de Tovar (Fig. 2).

17 "Tampoco se puede dezir q[ue] se deriva de otra voz que es Tlacati que quiere dezir nacer; porque, si saliera de ahí se dixera con propriedad del Caballo y del Leon y de los demas animales a quien conviene nacer. Y ninguno en la lengua los llama assi con este nombre de Tlacatl, ni tal se halla usado y del Angel y del Demonio, sí. Antes saben que el Demonio no nascio sino que fue arrojado, con fuerça diuina del cielo, como lo significan ellos mismos". 
deros Chriflianos y hazicodo ofras crrcaridad yomor de Dios merefean, por el valor de fu prefica sangre agui fu diuua gracia y derpues cl Cielo Amen.

G. Omnia qux in hoclopere continentur, facro Sandtę matris Ecelefiç rudicio \& corre Cioni fubiecta funto. wozespos 8

GTodos los infra efcriptos, dezimos, no auer vo cablo en la légua Mexicana, mejor y mas propio para declarar efte termino perfona diuina, enla Sanctifsima Trinidad, y dallo a entender a los In dios, que es T E OTLACA T L y efte lo es tan to que lo fignifica y declara, có tanta y mas propie dad que el que cómunmente vfamos en romance. $\mathbf{Y}$ efta muy bien prouada la conuinacion que tiené eftos dos nombres, perfona diuma Y T E OT LA C A TL. Y afsilo firmamos de nueftros nombres, como confta de nueftros pareceres, en el original el qual queda en el Archiuo de Sácto Domingo de Mexico.

Er Francilco de Solis. $\quad$ Fr. Francifeo Murios, Prior, Fr. Hieronimo de çarate. $\quad$ Fr. Diego de Cōtreras Miá Fr. Francifco de Rojas. Fr Alonfo de solis.

luan de Touar. luan de Ledefina.

Diegodosarirefteuan Auguftin Cono.

Francifco de Medias. Fr. Inan Baptiffa de Mondra
got Suprion.

Fig. 2: “Omnia quae...”. León, Martín de. Camino del cielo en lengva mexicana, 1611. Cortesía de la John Carter Brown Library.

El texto sigue a la dedicatoria del catecismo al Arzobispo de México y choca como una excentricidad con la tendencia ortodoxa y anti-idolátrica que, en principio, parece orientar el conjunto, destinado a desterrar para siempre los remanentes aztecas y demás vestigios de la fe previa. Sirve no obstante para discriminar entre la consideración herética que dichos vestigios merecían entre la curia española y la alta estima que, en cambio, ésta reserva a la antigua lengua mexica en la que se había adorado y sacrificado (Gil 45). En este aspecto, resulta cuando menos curioso observar la novedad de la opción propuesta y la unanimidad con que es acogida, puesto que en la lista de firmantes del documento se incluyen representantes de casi todas las órdenes activas en 
ese momento en Nueva España: dominicos, franciscanos, agustinos, desde confesores de indios como Francisco Muñoz, hasta un profesor de filosofía en el Seminario de San Ildefonso como es Juan de Ledesma ${ }^{18}$. Todos ellos están convencidos de la propiedad y exactitud con que el término Teotlacatl sirve a la apelación de Dios Padre, porque es vocablo potissimo y por "no haber otro que tan bien lo signifique".

IX. Según Derrida, el régimen traductor compete a la economía de una cultura, a la ley de propiedad de la misma, incluso si se aplica a un indecible impropio, una voz imposible y extranjera, algo así como una absoluto sin metonimia ni traslado al mundo de recepción al que se traduce ${ }^{19}$. Dios pertenece a esta tipología de palabras inapropiadas, por tanto intraducibles, cuya condición de arranque y a la vez de inefabilidad asegura por contraste y permite, a partir de ella, todas las traducciones. Al menos en el sorprendente documento de Martín de León funciona como el punto cero que legitima cualquier versión en idioma náhuatl, hace posible cualquier traducción y garantiza en efecto el ingreso en el paraíso de todos sus hablantes: un paraíso ahora multirracial y poliglósico, lejos ya de la exclusividad sustantiva de la lengua de Adán.

Todo lo que rodea su admisión, todo lo que se encuentra en esta clave de la palabra divina se inscribe en esta categoría común de lo que no se traduce, la declaración misma con la que, casi como un juramento, León compromete a sus colegas en la aceptación de otra nomenclatura, pertenece, de hecho, a la condición de traducción inapropiada, quizá porque no es paralelamente

18

Fernando Gil, que dedica un competente artículo a este documento, ofrece allí la biografía escueta de los firmantes: el provincial de los agustinos en 1601, Diego de Contreras; el jesuita cordobés y confesor de virreyes en Lima y Nueva España, Diego de Senestevan; el nacido en México, Agustín Cano, profesor de Teología y Sagrada Escritura; los ya mencionados Juan de Ledesma, criollo, Juan de Tovar, buen hablante de otomí, mazagua y náhuatl, Jerónimo de Zárate, misionero en el norte con Vázquez de Coronado y Juan de Oñate y el prior Francisco Muñoz. Por otra parte, es la primera vez que un término indígena se acepta tan amplia y consensuadamente para "transmitir el concepto de persona divina" (Gil 52). No lo encontramos de ese modo antes ni en Fray Bernardino de Sahagún ni en el Vocabulario de Fray Alonso de Molina.

19 Derrida señala que para poder hablar de la existencia de intraducibles en una lengua, es necesario partir de la traducción como un ejercicio económico que establece lo apropiado en función de lo apropiable, tentativa básicamente traductora (Derrida, Qu'est-ce Qu'une Traduction "relevante"?). 
objeto posible de apropiación ni del tipo de manejo al que la traducción da lugar. De hecho, el régimen del juramento no tiene competencia sobre lo celeste: no se jura el nombre de una deidad, puesto que es ella la invocada en dicho régimen como garante de lo jurado.

Lo señala de nuevo Derrida: una declaración jurada, una promesa no tienen traducción posible, forman la parte literal del lenguaje y suponen tomar al pie de la letra lo juramentado ${ }^{20}$. Por tanto, como acto perlocutivo que es, no puede trasladarse ni versionarse: no posibilita la apropiación o la propiedad que traducir algo exige, se sitúa en la obligación de una palabra denotativa, exactamente dada y tomada en la cerrazón sin alteraciones de su literalidad. Pero además Dios es un literal inapropiable: no es interpretable, no tiene otras versiones.

Ante el misterio de su nombre náhuatl, León y sus amigos solo pueden aseverar que esa voz de teocatl es su nombre más sensato, más adecuado, más incluso que el sustantivo que se le da en romance en una acción, la declaración firmada, el juramento, que nunca se realiza sino en el idioma de origen, que no puede tampoco traducirse: redoblado esfuerzo de intraducibilidad aplicado a demostrar la propiedad de una traducción. Pero también podríamos leerlo como un ejercicio de fascinación ante la peculiaridad expresiva del otro, como gesto de transculturación temprana por parte de estos hechizados traductores que aceptan, declaran y prometen su convicción en la superioridad ajena de lo traducido.

\section{BIBLIOGRAFÍA}

Acosta, José de. De procuranda indorum salute. Ed. De L. Pereña, V. Abril et al. Madrid: CSIC, 1987.

Ávila, Francisco de. Tratado de los evangelios que nuestra madre la iglesia propone en todo el año desde la primera dominica de Aduiento, hasta la vltima Missa de Difuntos, Santos de España, y añadidos en el nuevo rezado. Explicase el Evangelio, y se pone vn sermon

$20 \quad$ “C'est dans la langue humaine (élément de la traduction) une loi inflexible qui à la fois interdit la traduction de transaction mais commande le respect de la littéralité originale ou de la parole donnée. C'est une loi qui préside à la traduction tout en lui commandant le respect absolu, sans transaction, de la parole donnée dans sa lettre originale. Le serment, la foi jurée, l'acte de jurer, c'est la transcendance même, l'expérience du passage au-delà de l'homme, l'origine du divin ou, si on préfère, l'origine divine du serment"' (Derrida 37). 
en cada vno en las lenguas Castellana, y General de los Indios deste Reyno del Perù, $y$ en ellos donde dà lugar la materia, se refutan los errores de la Gentilidad de dichos Indios. [Lima: Imprenta de Pedro de Cabrera, 1648]

Breton, Raymond. Petit Catechisme ov Sommaire des Trois Premieres parties de la Doctrine Chrestienne. A Avxerre: Par Gilles Bovqvet, Imprimeur ordinaire du Roy, MDCLXIV [1664].

Burke, Peter y R. Po-Chia Hsia. Cultural Translation in Early Mondern Europe.New York: Cambridge University Press, 2007.

Burkhart, Louise M. The Slippery Earth. Nahua-Christian Moral Dialogue in Sixteen-Century Mexico. Tucson: University of Arizona Press, 1989.

Carochi, Horacio. Arte de la lengua Mexicana y Castellana. México: En Casa de Antonio de Espinosa, 1571.

Córdoba, Juan. Vocabulario en lengua çapoteca. En Mexico: Pedro Ocharte y Antonio Ricardo, 1578.

Decoster, Jean-Jacques (Ed.). Incas e indios cristianos. Elites indígenas e identidades cristianas en los Andes coloniales. Cuzco : centro de Estudios Regionales Andinos "Bartolomé de las Casas", 2002.

Dedenbach-Salazar, Sabine. "Dictionaries, Vocabularies, and Grammars of Andean Indigenous Languages", en Pillsbury, Joanne (Ed.), Guide to Documentary Sources for Andean Studies 1530-1900, I. Norman: University of Oklahoma Press, 2008, 235-265.

Derrida, Jacques. Qu'est-ce Qu'une Traduction “relevante”? Paris: L'Herne, 2005.

Durston, Alan. Pastoral Quechua. The History of Christian Translation in Colonial Peru, 1550-1650. Notre Dame, Indiana: University of Notre Dame Press, 2007.

Duviols, Pierre. La lutte contre les religions autochtones dans le Pérou colonial. Lima: IFEA, 1972.

Eire, Carlos M.N. "Early modern Catholic piety in translation". In Burke, Peter and R. Po-Chia Hsia (Eds.). Cultural Translation in Early Modern Europe. Cambridge, UK: Cambridge University Press, 2007, 83-100.

Gil, Fernando. "Discusiones en torno al uso del término persona divina en náhuatl. Fray Martín de León O.P. y su Camino del cielo (México 1611)”, Teología 74 (1999/2): 29-68.

Gruzinsky, Serge. "Individualization and Acculturation: Confession among the Nahuas of Mexico from the Sixteenth to the Eighteenth Century". En Schwaller, John F. The Church in Colonial Latin America. Wilmington: A Scholarly Resources Inc., 2000, 103-120.

Garcilaso de la Vega, Inca. “Apostillas a la Historia General de las Indias de Francisco López de Gómara”. Edición y comentario de José Luis Rivarola. Nueva Revista de Filología Hispánica 50.1 (2002): [59]-139.

Harrison, Regina. "Doctrinal Works". In Pillsbury, Joanne (Ed.). Guide to Documentary sources for Andean Studies 1530-1900, I. Norman: University of Oklahoma Press, 2008, 217-234.

Itier, César (1995). "La littérature quechua d'évangelisation (XVIe et XVIIe siècles) comme source etnolinguistique", Amerindia 19-20: 321-30.

Jooken, Lieve. "Descriptions of American Indian Words Forms in Colonial Missionary Grammars”. En En Gray, Edgard G. y Fiering, Norman (Eds.). The Languages Encounter in the Americas (1492-1800). New York, Oxford: Bregan Books, 2000, 293-310. 
Kartunnen, Frances y James Lockhart. Nahuatl in the Middle Years Language Contact Phenomena in Texts of the Colonial Period. Berkeley: University of California Press, 1976.

Klor de Alva, Jorge. "Languages, Politics, and Translation: Colonial Discourse and Classic Nahuatl in New Spain". En Warren, Rosanna. The Art of Translation. Voices from the Field. Boston: Northeastern University Press, 1989: 143-162.

León, Martín de. Camino del cielo en lengva mexicana, con todos los requisitos necessarios para conseguir este fin, con todo lo que un Xp[ist]iano deue creer, saber, y obrar desde el punto que tiene vso de razon, hasta que muere. En Mexico: En la Emprenta de Diego Lopez Daualos. Y acosta de Diego Perez de los Rios, Año. De. 1611.

Lienhard, Martin. "Traducir para dominar. El aparato colonial y la traducción del discurso de los indios y los esclavos africanos". Vasos comunicantes 2 (2004), http://www.acett.org/ ficha_vasos.asp?numero=28\&punto=4 (09/10/2008).

Lisi, Laura. "Traducir: descubrir nuevos mundos". Palabras e ideas: ida y vuelta. Actas del XXXVI Congreso I.I.L.I. Pier Luigi Croveto y Laura Sanfelice, editores. Roma, Editore Riuniti, 2008.

Lockhart, James. “Three Experiences of Culture Contact: Nahua, Maya, and Quechua”. En Hill Boone, Elizabeth and Tom Cummings (Eds.). Native Tradictions in the Postconquest World. Washington, DC: Dumbarton Oaks Research Library and Collection, 1998, 31-51.

MacCormack, Sabine. "The Heart Has Its Reasons: Predicaments of Missionary Christianity in Early Colonial Peru”. Hispanic American Historical Review 65/3 (1985): 443-466.

Mannheim, Bruce. "Gramática colonial, contexto religioso", en Decoster, Jean-Jacques (Ed.). Incas e indios cristianos. Élites indigenas e identidades cristianas en los Andes coloniales. Cuzco, Lima: Centro de Estudios Regionales Andinos Bartolomé de Las Casas, Instituto Francés de Estudios Andinos y Asociación Kuraka, 2002, 209-220.

"La memoria y el olvido en la política lingüística colonial”, Deixis 13 (1989): 13-45

The Language of the Inka since the European invasion. Austin: University of Texas Press, 1991.

Mendieta, Gerónimo de. Historia eclesiástica indiana (1597). Ed. Por Joaquín García Icazbalceta. México: Antigua Librería, Portal de Agustinos, 1870.

Mignolo, Walter. "On the Colonization of Amerindian Languages and Memories: Renaissance Theories of Writing and the Discontinuity of the Classical Tradition", Comparative Studies in Society and History, vol. 34, $\mathrm{n}^{\circ} 2$ (Apr., 1992): 301-330

Murillo Gallegos, Verónica. "En náhuatl y en castellano: El dios cristiano en los discursos franciscanos”, Estudios de cultura náhuatl 41 (2011), (11/03/2013). Reproducción digital en: http://www.historicas.unam.mx/publicaciones/revistas/nahuatl/pdf/ecn41/852.pdf

Palabras de evangelización, problemas de traducción. Fray Juan Bautista de Viseo y sus textos para confesores, Nueva España (siglo XVI). México: Universidad Autónoma de Zacatecas, 2009.

Oré, Luis Hieronymo de. Símbolo Católico Indiano, en el qual se declaran los myjterios de la Fe..., Impre $\iint_{o}$ en Lima: por Antonio Ricardo, 1598. 
Rituale seu Manuale Pervanum, et forma brevis administrandi apud Indos sacrosancta Baptismi, Pœnientice, Eucaristía, Matrimonij, \& Extremce vnctionis Sacramenta. Neapoli: Apud Io. Iacobum Carlinum, \& Constantinum Vitales, 1607.

Ossorio, Juan. Apologia, y declaracion en dialogos en la lengua mexicana, del symbolo de San Athanasio, y confessionario breve. En Mexico: Imprenta de Iuan Ruyz, Año 1653.

Payàs Puigarnau, Gertrudis. El revés del tapiz. Traducción y discurso de identidad en la Nueva España (1521-1821). Madrid, Frankfurt: Iberoamericana, Vervuert, 2010.

Ricard, Robert, La conquista espiritual de México. Ensayo sobre el apostolado y los métodos misioneros de las órdenes mendicantes en la Nueva España de 1523 a 1572. México: Fondo de Cultura Económica, 1986.

Rivarola, José L. "Para la Génesis De los Comentarios Reales: Edición y comentario de Las Apostillas Del Inca Garcilaso (y Otros) a La Historia General De Las Indias De F. López De Gómara". Nueva Revista De Filología Hispánica 50.1 (2002):

Roxo Mexía y Ocón, Ivan. Arte de la lengua general de los indios del Perv. Impresso en Lima: por Iorge Lopez de Herrera, en la Calle de la Carcel de Corte, Año de MDCXXXXVIII [1648].

Sahagún, fray Bernardino de. Coloquios y doctrina cristiana, con que los doce frailes de San Francisco enviados por el papa Adriano Sexto y por el emperador Carlos V convirtieron a los indios de la Nueva España en lengua mexicana y española. Estudio introductorio y versión al castellano de Miguel León Portilla. México: Universidad nacional Autónoma de México, 1986.

Historia general de las cosas de Nueva España. México: Conaculta, 2000.

San Jerónimo. Epistola ad Pammachium. En Ruíz Bueno, D. Cartas de San Jerónimo, Edición bilingüe. Madrid: Biblioteca de Autores Cristianos, 1962.

Schulte, Rainer and John Biguenet (Eds.). Theories of Translation. An Anthology of Essays from Dryden to Derrida. Chicago and London: The UNiversity of Chicago Press, 1992.

Taylor, Gerald. "La Plática Breve de la Doctrina Cristiana (1584)", Amerindia 25 (2000): 173-188.

"Supay". Camac, camay y camasca y otros ensayos sobre Huarochirí y Yauyos. (Travaux de l'Institut français d'études andines, 126 / Archivo de historia andina, 35). Lima: Institut français d'étudesandines (IFEA) - Centro Bartolomé de Las Casas (CBC), 2000, 19-34.

Tercero Catecismo y exposicion de la doctrina christiana por sermones: para que los curas y otros ministros prediquen y enseñen a los indios y a las demas personas conforme a lo que proveyo en el Santo Concilio Provincial de Lima el año pasado de 1583. Lima: En la oficina de la calle de San Jacinto, 1773.

Venuti, Lawrence. The Scandals of Translation. Towards an ethics of difference. London and New York: Routledge, 1998.

The Translator's Invisibility. A History of Translation. London and New York: Routledge, 1995. 
Vespucci, Amerigo. "Lettera di .... Delle Isole nuovamente trovate in quattro suoi viaggi" (1500-1502). In Bandini, Angelo Maria. Vita e lettere di Amerigo Vespucci. Florencia: Nella Stamperia all'insegna di Apollo, 1745, 1-121.

Zúñiga, Antonio de. "Carta de ..., al Rey Don Felipe II. Perú 15-VII-1579” [1579]. En Marqués de Pidal y Miguel Salva, Colección de documentos inéditos para la historia de España, 26: 87-121, Madrid: Imprenta Viuda de Calero, 1855. 